\title{
LIMITAÇÕES FOTOSSINTÉTICAS EM FOLHAS DE PLANTAS DE TOMATEIRO SUBMETIDAS A CRESCENTES CONCENTRAÇÕES SALINAS
}

\author{
Sandro Dan Tatagiba ${ }^{1}$, Gustavo Adolfo Bevitori Kling Moraes $^{2}$, Kelly Juliane Telles Nascimento ${ }^{3}$, Anelisa de \\ Figueiredo Peloso ${ }^{4}$
}

\begin{abstract}
RESUMO
O objetivo deste trabalho foi avaliar as trocas gasosas, os parâmetros de fluorescência da clorofila $a$, a concentração de pigmentos fotossintéticos e o potencial osmótico em plantas de tomateiro submetidas a crescentes concentrações salinas. Para esta finalidade, plantas de tomateiro do cultivar Santa Clara foram cultivadas em vasos de $5 \mathrm{dm}^{3}$ contendo solução nutritiva de Hoagland e submetidas aos tratamentos de 0, 50, 100 e $150 \mathrm{mmol} \mathrm{L}^{-1}$ de $\mathrm{NaCl}$. O experimento foi realizado em casa de vegetação no Campus da Universidade Federal de Viçosa, num delineamento inteiramente casualizado com quatro repetições. Cada unidade experimental foi constituída por um vaso contendo duas plantas. Os resultados mostraram que o potencial osmótico nas folhas e nas raízes apresentaram reduções significativas à medida que se aumentava a concentração de $\mathrm{NaCl}$ na solução nutritiva, detectando o aumento do estresse sobre as plantas. A utilização da energia para os processos fotossintéticos e a capacidade de dissipação do excesso de energia na maquinaria fotossintética foi comprometida pelas crescentes concentrações salinas impostas pelos tratamentos, reduzindo a fotossíntese e o rendimento fotoquímico, demonstrado pelas trocas gasosas e pelos parâmetros de fluorescência de clorofila $a$, evidenciando que houve dano ao aparato fotossintético na fase bioquímica. As concentrações de pigmentos fotossintéticos diminuíram significativamente com o aumento na concentração salina, limitando a absorção da radiação fotossinteticamente ativa.
\end{abstract}

Palavras-chave: estresse salino, fluorescência da clorofila $a$, Solanum lycopersicum, pigmentos fotossintéticos, trocas gasosas

\section{ABSTRACT \\ PHOTOSYNTHETIC LIMITATIONS IN LEAVES OF TOMATO PLANTS SUBJECTED TO INCREASING SALT CONCENTRATIONS}

The aim of this study was to evaluate gas exchange, fluorescence parameters of chlorophyll $a$, photosynthetic pigment concentration, and osmotic potential in tomato plants subjected to increasing salt concentrations. For this purpose tomato plants, cultivar Santa Clara, were grown in $5 \mathrm{dm}^{-3}$ pots containing Hoagland nutrient solution and subjected to treatments of $0,50,100$ and $150 \mathrm{mM} \mathrm{NaCl}$. The experiment was conducted in a greenhouse of the University Federal de Viçosa in a completely randomized design with four replications. Each experimental unit consisted of one pot containing two plants. The results showed that the osmotic potential in leaves and roots decreased significantly as the $\mathrm{NaCl}$ concentration in the nutrient solution increased by detecting the elevation of stress on the plants. The use of energy for the photosynthetic processes and dissipation of excess energy in photosynthetic machinery was compromised by increasing salt concentrations imposed by the treatments, reducing photosynthesis and photochemical efficiency demonstrated by gas exchange and the fluorescence parameters of chlorophyll $a$, indicating that there was damage to the photosynthetic apparatus in the biochemical phase. The photosynthetic pigments decreased significantly with increasing salt concentration, limiting the absorption of photosynthetically active radiation.

Keywords: salt stress, fluorescence of chlorophyll a, Solanum lycopersicum, photosynthetic pigments, gas exchange

Recebido para publicação em 11/11/2013. Aprovado em 19/03/2014.

1 - Engenheiro Agrônomo, Doutor em Fisiologia Vegetal, UFV/Viçosa-MG, E-mail: sandrodantatagiba@yahoo.com.br

2 - Engenheiro Agrônomo, Doutor em Fisiologia Vegetal, UFV/Viçosa-MG, E-mail: gustavo.kling@gmail.com

3 - Engenheira Agrônoma, Doutora em Fisiologia Vegetal, UFV/Viçosa-MG, E-mail: kellytelles@gmail.com

4 - Engenheira Agrônoma, UFV/Boa Esperança-MG, E-mail: anelisapeloso@yahoo.com.br

138 REVENG

138-149p. ENGENHARIA NA AGRICULTURA, VIÇOSA - MG, V.22 N.2, MARÇO / ABRIL 2014 


\section{INTRODUÇ̃̃O}

O tomateiro é a segunda hortaliça cultivada no mundo, registrando uma produção de 152.900 .000 toneladas (FAO, 2009), sendo superada apenas pela batata. Entre as hortaliças produzidas no Brasil, o tomate destaca-se como a principal, tanto no aspecto econômico como no social (MARTINS, 1992). O cultivo de tomate ocupa uma área de aproximadamente 64,88 mil hectares, na qual foi produzida em 2012, 4.091.825 toneladas, tendo o país uma produtividade média de 63,07 toneladas por hectare (IBGE, 2012).

A salinidade é um fator que limita o crescimento e a produtividade do tomateiro, podendo alterar a morfologia e o desenvolvimento, bem como processos fisiológicos e bioquímicos (NETO, 2005). O grau em que o estresse salino influencia o crescimento das plantas é dependente de muitos fatores, os quais se destacam a espécie vegetal, cultivar, estádio fenológico, composição salina do meio e condições edafoclimáticas (SHANNON, 1994).

Em condições de estresse salino, a redução na produtividade vegetal pode ser originada pelo desbalanço nutricional, quando a alta concentração de sódio no solo reduz a disponibilidade de potássio, cálcio e magnésio, ou quando o sódio desloca o cálcio ligado às membranas plasmáticas, alterando a sua integridade estrutural e funcional (MARSCHNER, 1995). A toxicidade por íons, quando o sódio é encontrado em altas concentrações nas plantas, pode interferir na estrutura e função de algumas enzimas, e também na função do sódio como cofator em várias reações. $\mathrm{O}$ estresse salino pode também intervir sobre o efeito osmótico, restringindo a absorção de água pelas raízes sob baixo potencial hídrico na solução do solo, podendo ocasionar queda do potencial de turgescência das células, comprometendo o crescimento (MARSCHNER, 1995).

Em muitos casos, a concentração de sais não atinge níveis osmóticos ou tóxicos capazes de prejudicar a absorção de água pelas plantas, no entanto, a concentração de diversos íons pode provocar interferências indiretas e ser um obstáculo à boa absorção de elementos essenciais e, consequentemente, ao desenvolvimento de um processo metabólico normal (MEDEIROS; GHEYI, 1997). Por outro lado, algumas espécies de plantas produzem rendimentos aceitáveis, sob condições salinas, em virtude da melhor adaptação osmótica, tendo maior capacidade de absorção de água, mesmo em potenciais osmóticos muito baixos (FLOWERS, 2004).

A redução no crescimento e na produtividade observada por muitas espécies sujeitas à salinidade muitas vezes estão associadas com a redução na capacidade fotossintética, devido aos processos de limitações estomáticas e não estomáticas (LORETO et al., 2003). A etapa bioquímica da fotossíntese pode ser afetada de maneira indireta por condições salinas como consequência do desbalanço nutricional e da queda de potencial de turgescência nas folhas. Estes fatores proporcionam o fechamento dos estômatos e aumento na resistência à entrada do $\mathrm{CO}_{2}$ na folha, acarretando diminuição na taxa fotossintética (LU; ZHANG, 1998).

A análise qualitativa e quantitativa da absorção e aproveitamento da energia luminosa através do fotossistema II (FS II) e possíveis relações com a capacidade fotossintética pode ser avaliada pela fluorescência da clorofila $a$ e tem se tornado uma ferramenta de importante aplicação em estudos de estresses abióticos, quando aliada a análise das trocas gasosas (KRAUSE; WEIS, 1991; ALLAHVERDIEV et al., 2000; MOUGET; TREMBLIN, 2002; NETTO et al., 2005). Esta técnica tem permitido um avanço no conhecimento dos processos fotoquímicos e não fotoquímicos que ocorrem na membrana dos tilacóides dos cloroplastos (ROHÁCEK, 2002), além de possibilitar o estudo de características relacionadas à capacidade de absorção e transferência da energia luminosa na cadeia de transporte de elétrons. De acordo com Krause e Weis (1991), é possível também estudar mudanças conformacionais ocorridas nos tilacóides o que tem sido ser útil na seleção genética à tolerância à salinidade (WEST, 1986; BELKHODJA et al., 1994; JIMENEZ et al., 1997).

Dessa forma, o objetivo deste estudo foi investigar as limitações fotossintéticas em folhas de tomateiro submetidos a crescentes concentrações salinas através das análises de trocas gasosas, 
dos parâmetros fornecidos pela fluorescência da clorofila $a$ e das concentrações de pigmentos fotossintéticos e do potencial osmótico.

\section{MATERIAL E MÉTODOS}

O experimento foi conduzido em casa de vegetação pertencente à Unidade de Crescimento de Plantas do Departamento de Biologia Vegetal da Universidade Federal de Viçosa, no município de Viçosa-MG, localizado a $20^{\circ} 45^{\prime} \mathrm{S}$ e $42^{\circ} 52^{\prime} \mathrm{W}$ e 648, $82 \mathrm{~m}$ de altitude.

O material vegetal utilizado foi o tomateiro (Solanum lycopersicum Mill) cultivar Santa Clara 5600 VF, da empresa Agroflora (Sakata). O semeio foi realizado em caixas plásticas sob leito de areia e as mudas com 2-3 folhas em desenvolvimento foram transferidas para vasos de $5 \mathrm{dm}^{3}$, contendo solução nutritiva à meia força, preparada de acordo com Hoagland e Arnon (1950), permanecendo por 15 dias. Após este período, quando as plantas apresentavam três folhas definitivas totalmente expandidas, foram iniciadas as aplicações dos tratamentos salinos. $\mathrm{O} \mathrm{NaCl}$ foi aplicado gradualmente com o objetivo de evitar danos severos às plantas, o qual foi adicionado com incrementos de $50 \mathrm{mmol} \mathrm{L}^{-1}$ a cada 12 horas, até atingir às concentrações finais de 50,100 e 150 mmol L ${ }^{-1}$ em solução nutritiva com força total (HOAGLAND; ARNON, 1950), permanecendo por 20 dias de experimentação. A solução nutritiva foi renovada a cada quatro dias e o $\mathrm{pH}$ da solução ajustado diariamente para 5,5 pela adição de $\mathrm{HCl}$ e $\mathrm{NaOH}$, ambos na concentração de $2 \mathrm{~mol} \mathrm{~L}^{-1}$.

Aos 35 dias de experimentação e 20 dias após o início das aplicações dos tratamentos salinos foram realizadas as avaliações fisiológicas. $\mathrm{O}$ potencial osmótico $\left(\Psi_{\mathrm{S}}\right)$ das folhas e raízes foi determinado pelo método crioscópico, sendo o ponto de congelamento da amostra obtido com auxílio de um microsmomêtro Osmette modelo 2007 (Precision Osmette, Precision Systems Inc., Natick, MA, USA).

A taxa de assimilação líquida de $\mathrm{CO}_{2}(A)$, condutância estomática $(g)$, taxa de transpiração $(E)$ e a razão da concentração interna e ambiente de $\mathrm{CO}_{2}\left(C / C_{a}\right)$ foram determinadas em um analisador de gás a infravermelho (IRGA, modelo portátil LI-
6400, LI-COR Biosciences Inc., Lincon, Nebraska, USA). Foi utilizada luz actínia constante de 1000 $\mu$ mol fotóns $\mathrm{m}^{-2} \mathrm{~s}^{-1}$, concentração de $\mathrm{CO}_{2}(\mathrm{Ca}) \mathrm{de}$, aproximadamente, $385 \mu \mathrm{mol} \mathrm{mol}^{-1}$ e temperatura do ambiente de $27{ }^{\circ} \mathrm{C} \pm 0,9$. As leituras foram realizadas entre as 9:00 e 10:30 horas.

Os parâmetros de fluorescência da clorofila $a$ foram obtidos a partir de um fluorômetro portátil com amplitude de pulso modulado (FMS2, Hansatech, Norfolk, Reino Unido). A fluorescência inicial $\left(\mathrm{F}_{0}\right)$, a fluorescência máxima $\left(\mathrm{F}_{\mathrm{m}}\right)$, a eficiência fotoquímica máxima do FS II $\left(\mathrm{F}_{\mathrm{v}} / \mathrm{F}_{\mathrm{m}}\right)$, o rendimento quântico efetivo do FS II (Y(II)), a taxa de transporte de elétrons (TTE) e o coeficiente de extinção não fotoquímica (NPQ) foram determinados nas mesmas folhas e horários em que foram realizadas as medições das trocas gasosas, sendo estimados como descrito por Genty et al. (1989), Bilger et al. (1995) e Lima et al. (2002).

Para a determinação dos pigmentos fotossintéticos, discos foliares de área conhecida $\left(0,785 \mathrm{~cm}^{2}\right)$ foram pesados e colocados em vidros contendo DMSO (Dimetilsulfóxido) saturado com carbonato de cálcio. Os vidros foram armazenados a $60{ }^{\circ} \mathrm{C}$ por uma hora (HISCOX; ISRAELSTAM, 1979). Alíquotas de $1,7 \mathrm{~mL}$ foram retiradas para leitura espectrofotométrica a 490, 646 e $663 \mathrm{~nm}$. Os teores de clorofila $a$, clorofila $b$, clorofila total e carotenóides foram determinados seguindo as equações propostas por Welburn (1994).

Os dados climáticos de temperatura e umidade relativa do ar foram obtidos utilizando um termohigrógrafo, instalado dentro da casa de vegetação onde foi conduzido o experimento.

$\mathrm{O}$ experimento foi instalado num delineamento inteiramente casualizado, com quatro tratamentos $\left(0,50,100\right.$ e $150 \mathrm{mmol} \mathrm{L}^{-1}$ de $\left.\mathrm{NaCl}\right)$ e quatro repetições. Cada unidade experimental foi constituída por um vaso contendo duas plantas. Os dados obtidos foram submetidos à análise de variância e as médias foram comparadas pelo teste de Tukey $(\mathrm{p} \leq 0.05)$ utilizando o software Statistical Analysis System (SAS) versão 6.12 para Windows ${ }^{\circledR}$, Cary: SAS Institute, NC, EUA, 1996.

\section{RESULTADOS E DISCUSSÃO}

As temperaturas máximas ( $\mathrm{T}$ máxima), 
médias ( $\mathrm{T}$ média) e mínimas ( $\mathrm{T}$ mínima) do ar durante o período experimental do cultivo de tomate estão mostradas na Figura 1a. Durante todo o período de desenvolvimento do tomateiro, as temperaturas médias mantiveram-se acima de $20{ }^{\circ} \mathrm{C}$, observando-se alguns valores que ultrapassaram $25{ }^{\circ} \mathrm{C}$. O tomateiro é uma planta sensível a altas e baixas temperaturas, requerendo temperaturas superiores a $10^{\circ} \mathrm{C}$ e inferiores a 35 ${ }^{\circ} \mathrm{C}$ para o bom desenvolvimento, e ainda para cada fase do desenvolvimento, requer uma faixa ótima de temperatura do ar, que em média está entre 15 a $25{ }^{\circ} \mathrm{C}$ (GÓMEZ et al., 2000; ADAMS; VALDÉS, 2002; ALVARENGA, 2004). A umidade relativa média do ar (UR média) manteve-se acima de $50 \%$, enquanto que os valores da umidade relativa máxima (UR máxima) e mínima (UR mínima) registradas foram de $88 \%$ e $24 \%$, respectivamente (Figura 1b).

$\mathrm{O} \Psi_{\mathrm{s}}$ nas folhas e nas raízes apresentaram reduções significativas à medida que se aumentava a concentração de $\mathrm{NaCl}$ na solução nutritiva, caracterizando o aumento crescente do estresse salino sobre as plantas (Quadro 1). Reduções significativas nos valores de $\Psi_{\mathrm{s}}$ em $42 \%$ e $58 \%$ nas folhas e raízes, respectivamente, foram encontradas nas plantas submetidas à concentração de $150 \mathrm{mmol}$ $\mathrm{L}^{-1}$ de $\mathrm{NaCl}$ em relação às plantas não submetidas ao $\mathrm{NaCl}$ ( $0 \mathrm{mmol} \mathrm{L}^{-1}$ de $\left.\mathrm{NaCl}\right)$, evidenciando que o tempo de exposição às concentrações salinas foi suficiente para promover um sinal de estresse percebido pelas raízes e folhas.

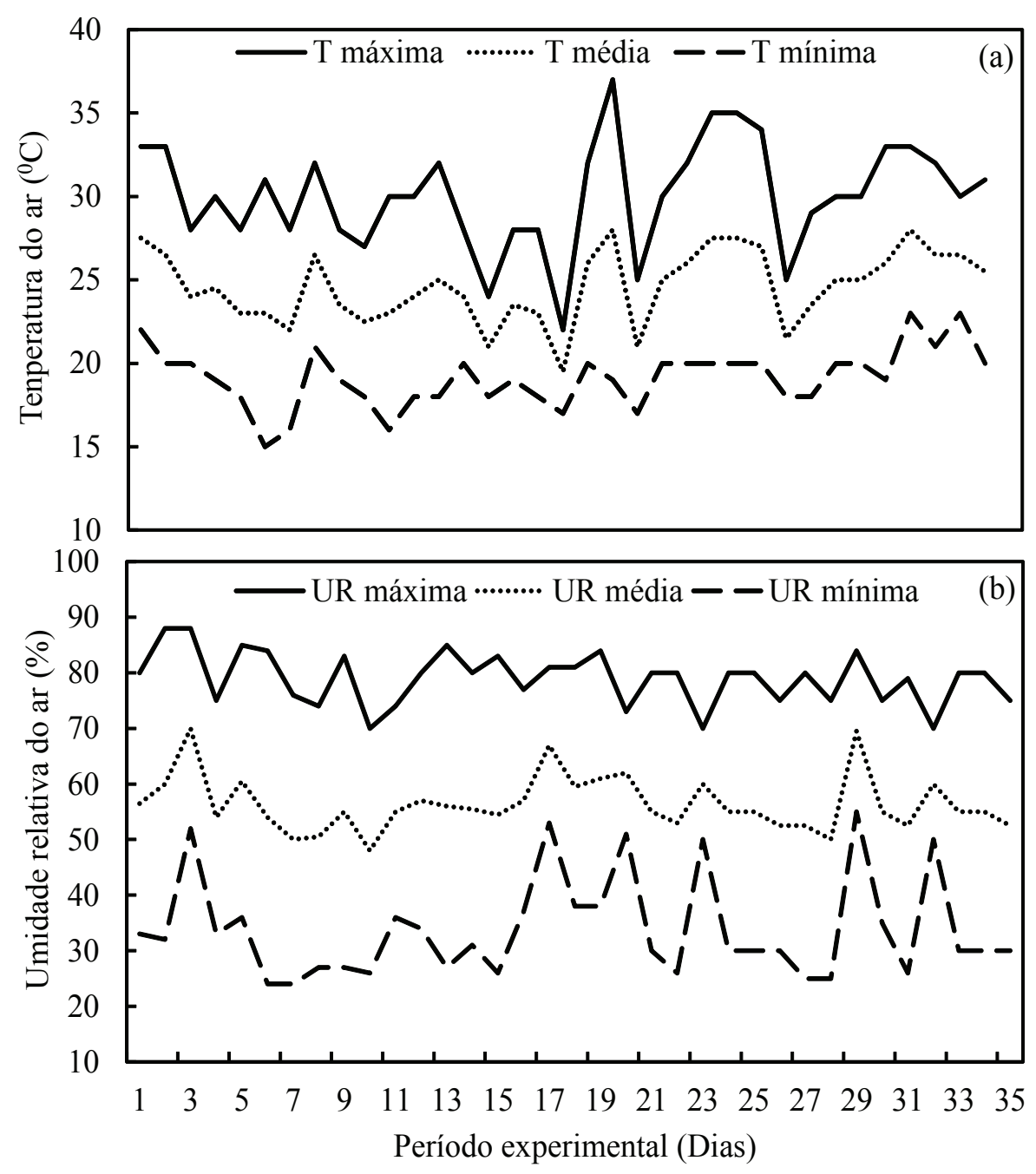

Figura 1. Temperatura (a) e umidade relativa do ar (b) durante o período experimental. 
Quadro 1. Potencial osmótico $\left(\Psi_{\mathrm{s}}\right)$ em folhas e raízes de plantas de tomateiro submetidas a crescentes concentrações salinas $\left(50,100\right.$ e $150 \mathrm{mmol} \mathrm{L}^{-1}$ de $\left.\mathrm{NaCl}\right)$ e não submetidas à concentração salina (0 mmol L-1 de $\mathrm{NaCl})$.

\begin{tabular}{ccc}
\hline \multirow{2}{*}{ Concentração salina $\left(\mathrm{mmol} \mathrm{L}^{-1}\right)$} & $\Psi_{\mathrm{s}}(\mathrm{MPa})$ \\
\cline { 2 - 3 } & Folhas & Raízes \\
\hline 0 & $-0,799 \mathrm{a}$ & $-0,176 \mathrm{a}$ \\
50 & $-0,852 \mathrm{a}$ & $-0,354 \mathrm{~b}$ \\
100 & $-1,226 \mathrm{~b}$ & $-0,359 \mathrm{~b}$ \\
150 & $-1,370 \mathrm{~b}$ & $-0,422 \mathrm{c}$ \\
\hline
\end{tabular}

Médias seguidas de letras diferentes na mesma coluna diferem significativamente entre si pelo teste Tukey a $5 \%$ de probabilidade

De acordo com Chaves et al. (2003), o $\mathrm{NaCl}$ em alta concentração pode promover um sinal de estresse salino que pode ser percebido pelas raízes como um estresse osmótico. $\mathrm{O}$ excesso de sais na solução pode reduzir a disponibilidade de água para as plantas, além de trazer problemas na distribuição de nutrientes específicos que atuam no metabolismo, afetando a fisiologia a tal ponto de comprometer o rendimento fotossintético e a produtividade (AYERS; WESTCOT, 1991).

Decréscimos nas variáveis de trocas gasosas nas folhas de tomateiro submetidas às crescentes concentrações salinas foram observados (Figura 2). A fotossíntese líquida $(A)$ apresentou reduções significativas de 34,37 e $59 \%$ nas plantas submetidas às concentrações de 50, 100 e 150 mmol L $\mathrm{L}^{-1}$ de $\mathrm{NaCl}$, respectivamente, em relação às plantas não submetidas ao estresse salino $(0$ mmol L-1) (Figura 2a). O estresse provocado pelas crescentes concentrações de sais também reduziu significativamente a condutância estomática $\left(g_{s}\right)$ em $67 \%$; nas plantas submetidas à concentração de $150 \mathrm{mmol} \mathrm{L}^{-1}$ de $\mathrm{NaCl} \mathrm{em}$ relação às plantas controle $\left(0 \mathrm{mmol} \mathrm{L}^{-1} \mathrm{de} \mathrm{NaCl}\right)$ (Figura 2b), observou-se a redução significativa da taxa transpiratória $(E)$ em $60 \%$ (Figura 2c), porém houve aumento significativo na relação $C / C_{a}$ em 33\% (Figura 2d). O decréscimo em $A$ encontrado nas plantas submetidas às crescentes concentrações salinas $\left(50,100\right.$, e $150 \mathrm{mmol} \mathrm{L}^{-1}$ de $\mathrm{NaCl}$ ) pode estar relacionado com a menor abertura estomática. $\mathrm{A} g_{s}$ pode ter diminuído devido a menor disponibilidade de água para as raízes, o que pode ser confirmado pelo estresse salino imposto pelo crescente aumento na concentração de $\mathrm{NaCl}$. Segundo Gulzar et al. (2003), o estresse salino diminui a assimilação de $\mathrm{CO}_{2}$, a condutância estomática e a transpiração das plantas. Contudo, aumenta a respiração e a concentração de carbono interno (KHAVARINEJAD; CHAPARZADEH, 1998). Vários trabalhos têm observado redução em $A$ em plantas submetidas a condições de estresse salino (EVERARD et al., 1994; MA et al., 1997; SCHMUTZ, 2000; MELONI et al., 2003, AZEVEDO 2009). No entanto, em sua maioria essa diminuição em $A$ é atribuída à redução na aquisição $\mathrm{CO}_{2}$ pelo fechamento estomático.

Além do fechamento estomático, outras limitações, não estomáticas, podem estar ocorrendo como indicado pelo aumento da relação $C_{i} / C_{a}$ (Figura 2d). Considerando-se que a concentração de $\mathrm{CO}_{2}$ externa $\left(C_{a}\right)$ mantenha-se constante, o aumento na relação $C / C_{a}$ deve-se apenas às variações na concentração interna $\left(C_{i}\right)$. Se $C i$ está aumentando, significa que o $\mathrm{CO}_{2}$ que está chegando às células do mesófilo não está sendo fixado na fase de carboxilação da ribulose 1,5 bifosfato carboxilase-oxigenase (Rubisco), possivelmente por danos em sua estrutura, reduzindo então a taxa fotossintética.

Aumento na relação $C_{i} / C_{a}$ também foi evidenciado por Everard et al. (1994) em plantas de

\section{REVENG 138-149p.}



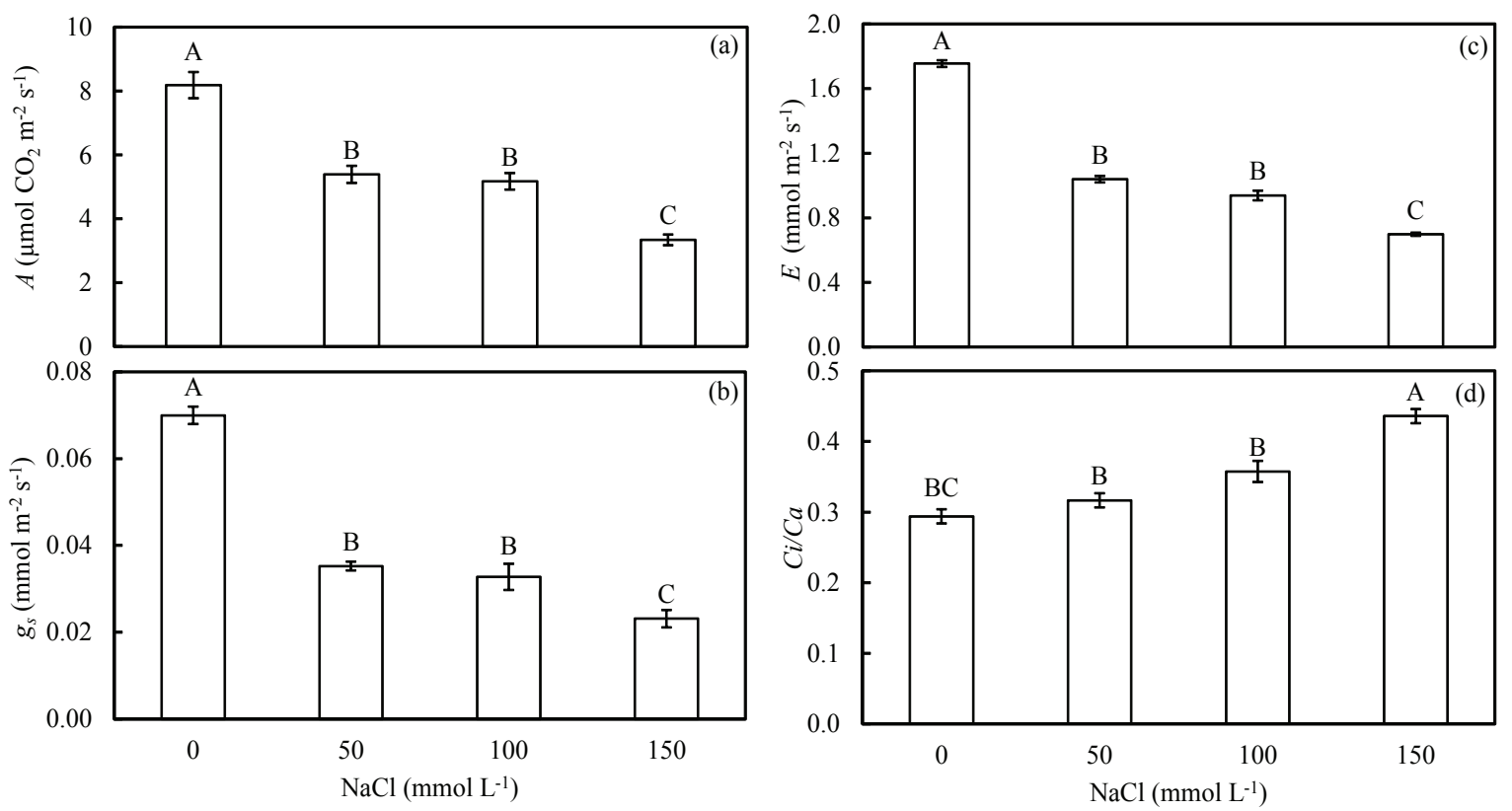

Figura 2. Fotossíntese líquida $(A)$ (a), condutância estomática $\left(g_{\mathrm{s}}\right)(\mathrm{b})$, taxa de transpiração $(E)(\mathrm{c})$ e concentração interna e ambiente de $\mathrm{CO}_{2}\left(C / C_{a}\right)(\mathrm{d})$ em folhas de plantas de tomateiro submetidas a crescentes concentrações salinas $\left(50,100\right.$ e $150 \mathrm{mmol} \mathrm{L}^{-1}$ de $\left.\mathrm{NaCl}\right)$ e não submetidas à concentração salina $\left(0 \mathrm{mmol} \mathrm{L}^{-1}\right.$ de $\left.\mathrm{NaCl}\right)$. Médias seguidas de letras diferentes na coluna diferem significativamente entre si pelo teste de Tukey a $5 \%$ de probabilidade. Barras em cada coluna representam o erro padrão da média.

aipo na maior concentração salina $\left(300 \mathrm{mmol} \mathrm{L}^{-1} \mathrm{de}\right.$ $\mathrm{NaCl}$ ), devido ao acúmulo do $\mathrm{CO}_{2}$ interno à folha. Em Argyranthemum coronopifolium, também sob condições de estresse salino, a condutância estomática e a taxa fotossintética diminuíram, no entanto, quando restabelecida as condições normais após 17 dias de estresse, a condutância estomática voltou ao normal, enquanto que a fotossíntese continuou inalterada, o que evidencia dano ao aparato fotossintético na fase bioquímica ou na fase de carboxilação da fotossíntese sob condições salinas (HERRALDE et al., 1998).

Reduções significativas na concentração de clorofila $a$ em 34\% (Figura 3a); de clorofila $b$ em 56\% (Figura 3b), de clorofila total em $40 \%$ (Figura 3c) e de carotenóides em 41\% (Figura 3d) foram obtidas nas folhas das plantas submetidas a concentração de $150 \mathrm{mmol} \mathrm{L}^{-1}$ de $\mathrm{NaCl} \mathrm{em}$ comparação as plantas não submetidas ao estresse salino (0 $\mathrm{mmol} \mathrm{L}^{-1}$ de $\left.\mathrm{NaCl}\right)$.

Estes resultados estão de acordo com os de Azevedo (2009), que também encontrou redução significativa no teor de clorofila $a, b$ e carotenóides em tomateiro. A salinidade, da mesma forma, causou diminuição significativa nos conteúdos de clorofila $a, b$ e carotenóides de folhas de Bruguiera parviflora (PARIDA et al. 2004). Segundo Londstreth e Nobel (1979), os conteúdos de clorofila e carotenóides diminuem sob altas concentrações de sais. No presente trabalho, as reduções significativas encontradas em $A$ podem também ser atribuída à perda de pigmentos fotossintéticos nas folhas de tomateiro imposta pelas crescentes concentrações salinas, uma vez que clorofilas e carotenóides são parte integrante do complexo antena de captação de luz para o processo fotossintético (TAIZ; ZEIGER, 2009). Danos causados nesses pigmentos afetam a atividade fotossintética das plantas (LARCHER, 2005).

Os parâmetros de fluorescência da clorofila $a$ fornecem informações úteis sobre a atividade do FSII e possíveis alterações no metabolismo fotossintético em folhas de plantas submetidas ao 

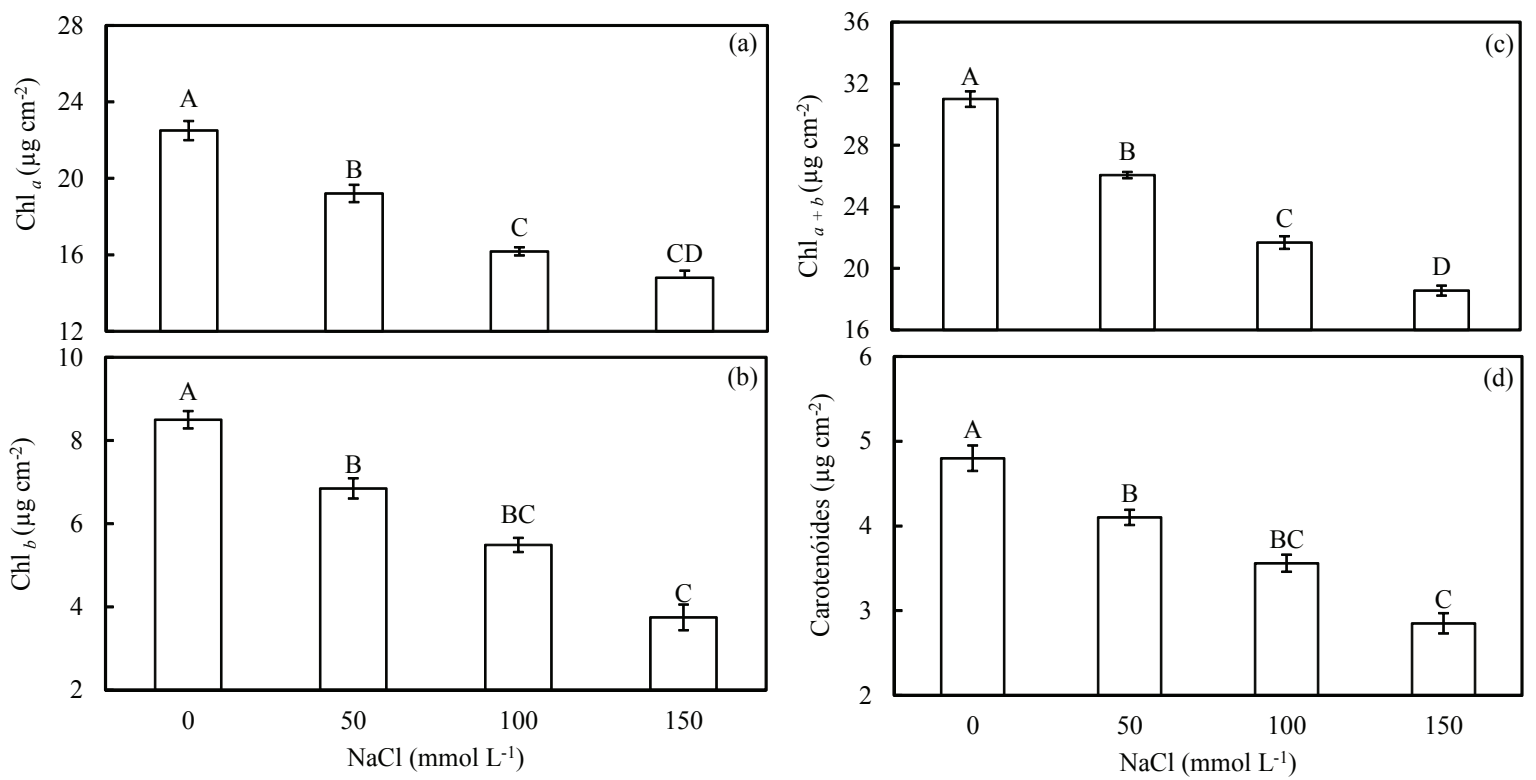

Figura 3. Concentração de clorofila $a\left(\mathrm{Chl}{ }_{a}\right)(\mathrm{a})$, clorofila $b\left(\mathrm{Chl}{ }_{b}\right)(\mathrm{b})$, clorofila total $\left(\mathrm{Chl}{ }_{a+b}\right)(\mathrm{c}) \mathrm{e}$ carotenóides (d) em folhas de plantas de tomateiro submetidas a crescentes concentrações salinas $\left(50,100\right.$ e $150 \mathrm{mmol} \mathrm{L}^{-1}$ de $\left.\mathrm{NaCl}\right)$ e não submetidas à concentração salina $\left(0 \mathrm{mmol} \mathrm{L}^{-1}\right.$ de $\mathrm{NaCl}$ ). Médias seguidas de letras diferentes na coluna diferem significativamente entre si pelo teste de Tukey a $5 \%$ de probabilidade. Barras em cada coluna representam o erro padrão da média.

estresse salino (ZANANDREA et al., 2006). De modo geral, a redução significativa encontrada para os parâmetros de fluorescência da clorofila $a$, $\mathrm{F}_{0}, \mathrm{~F}_{\mathrm{m}}, \mathrm{F}_{\mathrm{v}} / \mathrm{F}_{\mathrm{m}}, \mathrm{Y}(\mathrm{II})$ e TTE nas plantas submetidas as crescentes concentrações de $\mathrm{NaCl}$ mostram que o rendimento fotossintético foi reduzido pelo estresse salino (Figura 4).

Os menores valores encontrados para $\mathrm{F}_{0}$ nas plantas submetidas às crescentes concentrações de $\mathrm{NaCl}$ evidenciam que ocorreram alterações estruturais nos pigmentos fotossintéticos comprometendo, assim, a eficiência da energia de excitação a partir da antena coletora de luz e danos aos centros de reação do FSII (Figura 4a). Reduções nas concentrações dos pigmentos fotossintéticos nas folhas das plantas submetidas às crescentes concentrações salinas suportam essa hipótese. Tendência semelhante aos resultados obtidos para $\mathrm{F}_{0}$ ocorreu para $\mathrm{F}_{\mathrm{m}}$ (Figura $4 \mathrm{~b}$ ). Assim, parece ocorrer uma deficiência na fotorredução da quinona $A\left(Q_{A}\right)$ e no fluxo de elétrons entre os fotossistemas. De Las Rivas e Barber (1997) relataram que a perda de atividade do FSII está provavelmente associada com a diminuição da capacidade de reoxidação das quinonas resultando em menor eficiência no transporte de elétrons para o fotossistema I (FSI).

A máxima eficiência na qual a luz é absorvida pelo FSII para reduzir $Q_{A}$, representa por $F_{v} /$ $\mathrm{F}_{\mathrm{m}}$, é um indicador sensível do desempenho fotossintético das plantas, com valores ótimos entre 0,75 a 0,85 para a maioria das espécies (BOLHÀRNORDENKAMPF et al., 1989). Nas

plantas submetidas às crescentes concentrações salinas, os valores de $F_{v} / F_{m}$ foram significativamente menores em relação aos encontrados para as plantas controle $(0 \mathrm{mM}$ de $\mathrm{NaCl})$, evidenciando que pode ter havido dano no aparato fotossintético durante a salinização.

A maior parte dos resultados apresentados na literatura mostra que plantas submetidas ao estresse salino não apresentaram alterações na razão $\mathrm{F}_{\mathrm{v}} / \mathrm{F}_{\mathrm{m}}$ (DEBOUBA et al., 2007). Entretanto, Ghanem et al. (2008) e Azevedo (2009) registraram queda nos valores de $\mathrm{F}_{\mathrm{v}} / \mathrm{F}_{\mathrm{m}}$ em plantas de tomateiro após 15 dias de tratamento com crescentes concentrações salinas.

\section{REVENG}

138-149p. ENGENHARIA NA AgriCULTURA, VIÇOSA - MG, V.22 N.2, MARÇO / ABRIL 2014 
O desempenho fotossintético das plantas submetidas às crescentes concentrações salinas também pode ser evidenciado pelo rendimento quântico efetivo do FSII (Y(II)) (KLUGHAME; SCHREIBER, 2008). Os menores valores observados por esse parâmetro nas plantas submetidas às concentrações salinas fornecem um indicativo de que a fotossíntese foi reduzida, levando a uma queda significativa de $49 \%$ nas plantas submetidas a $150 \mathrm{mmol} \mathrm{L}^{-1}$ de $\mathrm{NaCl} \mathrm{em}$ comparação as plantas controles $\left(0 \mathrm{mmol} \mathrm{L}^{-1}\right.$ de $\mathrm{NaCl}$ ) (Figura 4d).

A salinidade também pode diminuir o transporte de elétrons utilizados na fotossíntese (REDDY et al., 1992), fato este ocorrido no presente trabalho. Nota-se na Figura 4e, que a TTE foi significativamente reduzida em 9,18 e $49 \%$ nas plantas submetidas às concentrações de $50,100 \mathrm{e}$ $150 \mathrm{mmol} \mathrm{L}^{-1}$ de $\mathrm{NaCl}$, respectivamente, quando comparadas com as plantas controle $\left(0 \mathrm{mmol} \mathrm{L}^{-1}\right.$ de $\mathrm{NaCl}$ ). De acordo com Verslues et al. (2006), a concentração elevada de sais aumenta o potencial osmótico, que reduz a disponibilidade de água para plantas. Este aumento no potencial osmótico inativa tanto os transportadores de elétrons fotossintéticos quanto os respiratórios (PAPAGEORGIOU et al., 1998; ALLAKHVERDIEV et al., 1999), podendo levar a inativação irreversível da via de transporte de elétrons fotossintéticos por proteínas (ALLAKHVERDIEV et al., 2000).
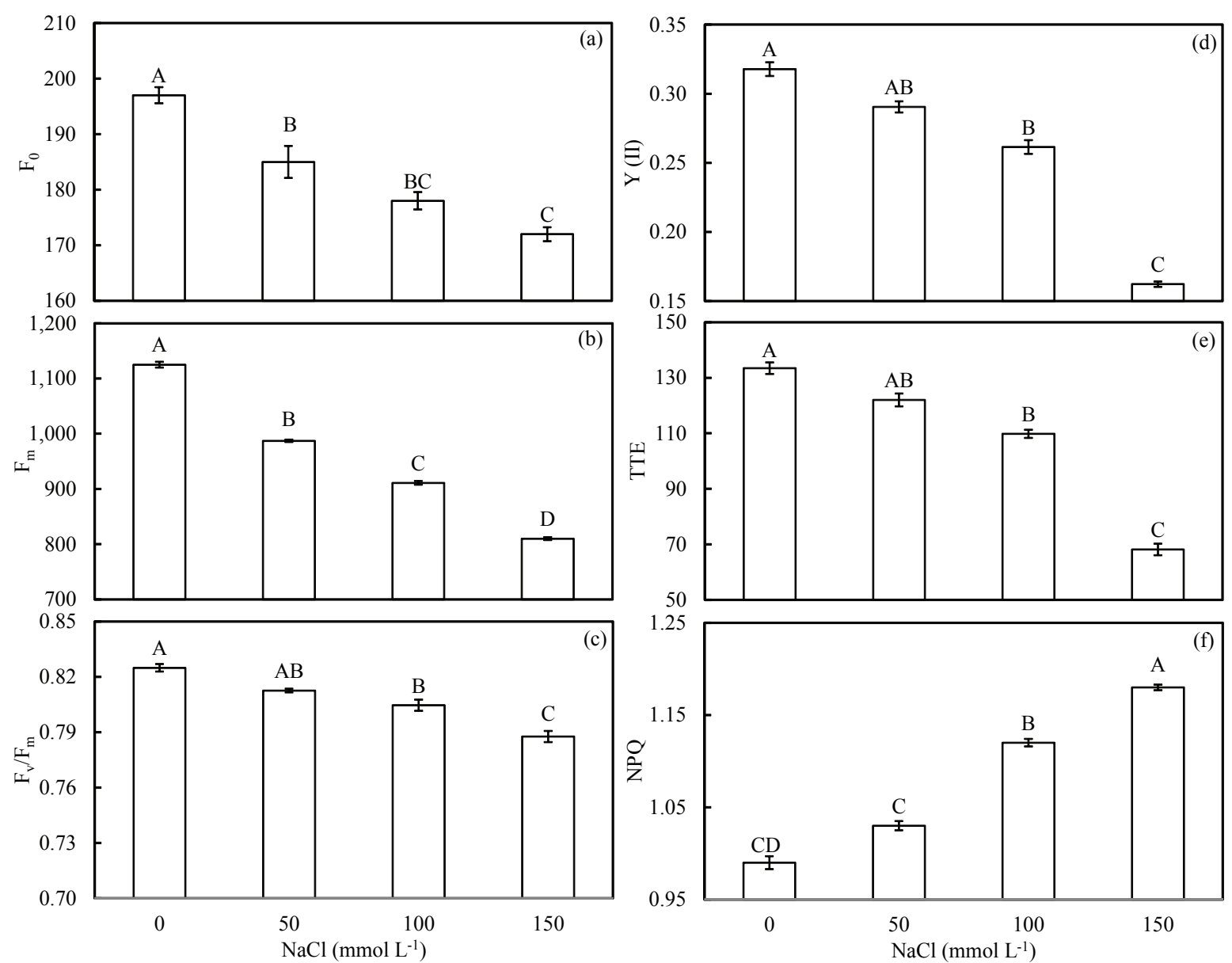

Figura 4. Fluorescência mínima $\left(\mathrm{F}_{0}\right)$, fluorescência máxima $\left(\mathrm{F}_{\mathrm{m}}\right)$, rendimento quântico máximo do $\mathrm{FS}$ II $\left(\mathrm{F}_{\mathrm{v}} / \mathrm{F}_{\mathrm{m}}\right)$, rendimento quântico efetivo do FSII (Y(II)), taxa de transporte de elétrons (TTE) e coeficiente de extinção não fotoquímica (NPQ) em folhas de plantas de tomateiro submetidas a crescentes concentrações salinas $\left(50,100\right.$ e $150 \mathrm{mmol} \mathrm{L}^{-1}$ de $\left.\mathrm{NaCl}\right)$ e não submetidas à concentração salina $\left(0 \mathrm{mmol} \mathrm{L} \mathrm{L}^{-1}\right.$ de $\left.\mathrm{NaCl}\right)$. Médias seguidas de letras diferentes na coluna diferem significativamente entre si pelo teste de Tukey a $5 \%$ de probabilidade. Barras em cada coluna representam o erro padrão da média. 
O coeficiente de extinção não fotoquímica (NPQ) aumentou significativamente em 5, 13 e $16 \%$ nas plantas submetidas às concentrações de 50,100 e $150 \mathrm{mmol} \mathrm{L}^{-1}$ de $\mathrm{NaCl}$, respectivamente, quando comparadas com as plantas controle $(0$ mmol L-1 de $\mathrm{NaCl}$ ), indicando menor aproveitando da energia de excitação para o quenching fotoquímico, a qual é dissipada na forma de energia luminosa. Ao contrário, os menores valores de NPQ encontrado nas plantas não submetidas ao estresse salino $\left(0 \mathrm{mmol} \mathrm{L}^{-1}\right.$ de $\left.\mathrm{NaCl}\right)$, permitem deduzir que a eficiência de utilização da energia luminosa e sua conversão em energia química foi maior, aumentando a eficiência da atividade fotossintética. Estes resultados estão semelhantes aos encontrados por Azevedo (2009), que verificou aumento nos valores de NPQ em plantas de tomateiro submetidos ao estresse salino.

\section{CONCLUSÕES}

- O estresse provocado pelas crescentes concentrações de sais diminuiu $A$ e $E$, os quais estiveram associados à redução em $g_{s}$;

- As concentrações de pigmentos fotossintéticos diminuíram com o aumento da concentração salina limitando a absorção da radiação fotossinteticamente ativa pelas plantas;

- A utilização da energia para os processos fotossintéticos e a capacidade de dissipação do excesso de energia na maquinaria fotossintética foi comprometida pelas crescentes concentrações salinas, reduzindo o rendimento fotoquímico demonstrado pelos parâmetros de fluorescência de clorofila $a$;

- Danos nas estruturas dos cloroplastos e limitações bioquímicas podem ter sido responsáveis pela redução da fotossíntese e estudos futuros devem se concentrar nos mecanismos associados a essa resposta.

\section{REFERÊNCIAS BIBLIOGRÁFICAS}

ADAMS, S.R.; VALDÉS, V.M. The effect of periods of high temperature and manipulating fruit load on the pattern of tomato yields. The Journal of Horticultural Science \& Biotechnology, v.77, p.461-466, 2002.
ALLAKHVERDIEV, S.I.; SAKAMOTO, A.; NISHIYAMA, Y.; INABA, M.; MURATA, N. Ionic and osmotic effects of $\mathrm{NaCl}$-induced inactivation of photosystems I and II in Synechococcus sp. Plant Physiology, v.123, p.1047-1056, 2000.

ALVARENGA, M.A.R. Tomate: produção em campo, em casa de vegetação e em hidroponia. Lavras: UFLA, 2004. 400p.

AYERS, R.S.; WESTCOT, D.W. Qualidade de água na agricultura. Tradução de Gheyi $H R$, Medeiros JF, Damasceno FAV. Campina Grande: UFPB, 1991. 218p.

AZEVEDO, L.C. Mecanismos de adaptação e fotoproteção em tomateiros submetidos ao estresse salino. 2009. 52p. Dissertação de Mestrado - Universidade Federal de Viçosa, Viçosa, 2009.

BELKHODJA, R.; MORALES, F.; ABADÍA, A.; GÓMEZ-APARISI, J.; ABADÍA, J. . Chlorophyll fluorescence as a possible tool for salinity tolerance screening in barley (Hordeum vulgare L.). Plant Physiology, v.104, p.667-673, 1994.

BILGER, W.; SCHREIBER, U.; BOCK. Determination of the quantum efficiency of photosystem II and of non-photochemical quenching of chlorophyll fluorescence in the field. Oecologia, v.102, p.425-432, 1995.

BOLHAR-NORDENKAMPF, H.R.; LONG, S.P.; BAKER, N.R.; OQUIST, G.; SCHREIBER, U.; LECHNER, E.G. Chlorophyll fluorescence as probe of the photosynthetic competence of leaves in the field: a review of current instrumentation. Functional Ecology, v.3, p.497-514, 1989.

CHAVES, M.M.; MAROCO, J.P.; PEREIRA, J.S. Understanding plant responses to drought from genes to the whole plant. Functional Plant Biology, v.30, p.239-264, 2003.

DEBOUBA, M.; HABIB, M.; GOUIA, G.H. Effects of nitrogen deficiency and $\mathrm{NaCl}$ on chlorophyll fluorescence of PSII in tomato (Solanum lycopersicon Chibli F1). Acta Botany Gallica, v.154, p.635-642, 2007. 
DE LAS RIVAS, J.; BARBER, J. Structure and thermal stability of photosystem II reaction centers studied by infrared spectroscopy. Biochemistry, v.36, p.8897-8903, 1997.

EVERARD, J.D.; GUCCI, R.; KANN, S.C.; FLORE, J.A.; LOESCHER, W.H. Gas exchange and carbon partitioning in the leaves of celery (Apium graveolens L.) at various levels of root zone salinity. Plant Physiology, v.106, p.281-292, 1994.

\section{FAO-FOODAGRICULTURALORGANIZATION}

TRADE YEAR-BOOK, Roma, v.59. 2009.

FLOWERS, T.J. Improving crop salt tolerance. Journal of Experimental Botany, v.55, p.307319, 2004.

GENTY, B.; BRIANTAIS, J.M.; BAKER, N.R. The relationship between the quantum yield of photosynthetic electron transport and quenching of chlorophyll fluorescence. Biochimica et Biophysica Acta, v.990, p.87-92, 1989.

GHANEM, M.E.; ALBACETE, A.; MATÍNEZANDUJAR, C.; ACOSTA, M.; ROMEROARANDA,R.;DODD,I.C.;LUTTS, S.;ALFOCEA, F.O. Hormonal changes during salinity-induced leaf senescence in tomato (Solanum lycopersicum L.). Journal of Experimental Botany, v.59, p.3039-3050, 2008.

GÓMEZ, O.; CASANOVA, A.; LATERROT, H.; ANAIS, G. Mejora genética y manejo del cultivo de tomate para la producción en el Caribe. $\mathrm{La}$ Habana, Instituto de Ivestigaciones Horticolas "Liliana Dimitrova", 2000. 159p.

GULZAR, S.; KHAN, M.A.; UNGAR, I.A. Salt tolerance of a coastal salt marsh grass. Communications in Soil Science and Plant Analysis, v.34, p.2595-2605, 2003.

HERRALDE， F.D.; BIEL， C.; SAVÉ, R.; MORALES, M.A.; TORRECILIAS, A.; ALARCÓN, J.J.; SÁNCHEZ-BLANCO, M.J. Effect of water and salt stresses on the growth, gas exchange and water relations in Argyranthemum coronopifolium plants. Plant Science, v.139, p.917, 1998.

HISCOX, J.D.; ISRAELSTAM, G.F. A method for the extraction of clhlorophyll from leaf tissue without maceration. Canadian Journal of Botany, v.57, p.1332-1334, 1979.

HOAGLAND, D.R.; ARNON, D.I. The waltercultured method for growing without soil. California Agricultural Experiment Station, (Circular, 347), 1950, 32p.

IBGE - Instituto Brasileiro de Geografia e Estatística. Levantamento Sistemático da produção Agrícola. Rio de Janeiro, v.25, n.02, p.1-88, 2012.

JIMENEZ, M.S.; GONZALEZ-RODRIGUEZ, A.M.; MORALES, D.; CID, M.C.; SOCORRO, A.R.; CABALLÉRO, M. Evaluation of chlorophyll fluorescence as a tool for salt stress detection in roses. Photosynthetica, v.33, p.291-301, 1997.

KHAVARINEJAD, R.A.; CHAPARZADEH, N. The effects of $\mathrm{NaCl}$ and $\mathrm{CaCl}_{2}$ on photosynthesis and growth of alfalfa plants. Photosynthetica, v.35, p.461-466, 1998.

KLUGHAMMER, C.; SCHREIBER, U. Complementary PSII quantum yield calculated from simple fluorescence parameters measured by PAM fluorometry and saturation pulse method. PAM Application Notes, v.1, p.27-35, 2008.

KRAUSE, G.H.; WEIS. E. Chlorophyll fluorescence and photosynthesis: the basic. Annual Review of Plant Physiology and Plant Molecular Biology, v.42, p.313-349, 1991.

LARCHER, W. Ecofiosiologia Vegetal. São Carlos: Rima, 2004 531p.

LIMA, A.L.S.; DA MATT, F.M.; PINHEIRO, H.A.; TÓTOLA, M.R.; LOUREIRO, M.E. Photochemical responses and oxidative stress in two clones of Coffea canephora under water deficit 
conditions. Environmental and Experimental Botany, v.47, p.239-247, 2002.

LONGSTRETH, D.J.; NOBEL, P.S. Salinity effects on leaf anatomy. Plant Physiology, v.63, p.700-703, 1979.

LORETO, F.; CENTRITTO, M.; CHARTZOULAKIS. Photosynthetic limitations in olive cultivars with diferente sensitivity to salt stress. Plant, Cell an Environment, v.26, p.959601, 2003.

LU, C.; ZHANG, J. Thermostability of photosystem II is increased in salt-stressed sorghum. Australian Journal of Plant Physioloy, v.25, p.317-324, 1998.

MA, H. C.; FUNG, L.; WANG, S.S.; ALTMAN, A.; HUTTERMANN, A. Photosynthetic response of Populus euphratica to salt stress. Florest Ecology and Management, v.93, p.55-61, 1997.

MARSCHNER, H. Mineral nutrition of higher plants. $2^{\mathrm{a}}$ ed. London: Academic Press, 1995. 889p.

MARTINS, G. Uso de casa de vegetação com cobertura plástica na tomaticultura de verão. 1992. 65p. Tese de Doutorado - Universidade Estadual Paulista "Júlio de Mesquita Filho", Jaboticabal. 1992.

MEDEIROS, J.F.; GHEYI, H.R. Manejo do sistema solo-água planta em solos afetados por sais. In: GHEYI, H.R.; QUEIROZ, J.E.; MEDEIROS, J.F. Manejo e controle da salinidade na agricultura irrigada, Campina Grande: UFPB, SBEA, p.239-284, 1997.

MELONI, D.A.; OLIVA, M.A.; MATINEZ, C.A.; CAMBRAIA, J. Photosynthesis and activity of superoxide dismutase, peroxidase and glutathione reductase in cotton under salt stress. Environmental and Experimental Botany, v.49: p.69-76, 2003.

MOUGET, J.; TREMBLIN, G. Suitability of the fluorescence monitoring system (FM, Hansatech) for measurement of photosynthetic characteristics in algae. Aquatic Botany, v.74, p.19-231, 2002.

NETO, A.D.A. Estresse salino, estresse oxidativo e tolerância cruzada em plantas de milho. In: Estresses ambientais: danos e benefícios em plantas. NOGUEIRA, R.M.C.; ARAÚJO, E.L.; WILLADINO, L.G. Recife ; UFRPE, Imprensa Universitária, 2005. 500p.

NETTO, A.T.; CAMPOSTRINI, E.; OLIVEIRA, G.J.; BRESSAN-SMITH, R.E. Photosynthetic pigments, nitrogen, chlorophyll a fluorescence and SPAD-502 readings in coffee leaves. Scientia Horticulturae, v.104, p.199-209, 2005.

PAPAGEORGIOU, G.C.; ALYGIZAKI-ZOBRA, A.; LADAS, N.; MURATA, N. A method to probe the cytoplasmic osmolarity and osmotic water and solute fluxes across the cell membrane of cyanobacteria with Chl $a$ florescence: experiments with Synechococcus sp. Physiologia Plantarum, v.103, p.215-224, 1998.

PARIDA, A.K.; DAS, A.B.; MITTRA, B. Effects of salt on growth, ion accumulation photosynthesis and leaf anatomy of the mangrove, Bruguiera parviflora. Trees - Structure and Function, v.18, p.167-174, 2004.

REDDY, M.P.; SANISH, S.; IYENGAR, E.R.R. Photosynthetic studies and compartmentation of ions in different tissues of Salicornia brachiata Roxb. under saline

conditions. Photosynthetica, v.26, p.173-179, 1992.

ROHÁCEK, K. Chlorophyll fluorescence parameters: the definitions, photosynthetic meaning, and mutual relationships. Photosynthetica, v.40, p.13-29, 2000.

SCHMUTZ, U. Effect of salt stress $(\mathrm{NaCl})$ on whole plant $\mathrm{CO}_{2}$-gas exchange in mango. Acta Horticulturae, v.509, p.269-276, 2000.

STATISTICAL Analysis System. 6.12 versão para Windows ${ }^{\circledR}$. Cary: SAS Institute, 1996. 
SHANNON, M.C.; GRIEVE, C.M.; FRANCOIS, L.E. Whole-plant response to salinity. In: Wilkinson RE. Plant environment interactions. New York: Marcel Dekker, 1994. p.199-244.

TAIZ, L.; ZEIGER, E. Fisiologia vegetal. $4^{\mathrm{a}}$ ed. Porto Alegre: Artemed, 2009. 848p.

VERSLUES, P.E.; AGARWAL, M.; KATIYARAGAWAL, S.; ZHU, J.K. Methods and concepts in quantifying resistance to drought, salt and freezing, abiotic stresses that affect plant water status. The Plant Journal, v.45, p.523-539, 2006.
WELLBURN, A.R. The spectral determination of chlorophyll $a$ and $b$, as well as total carotenoids, using various solvents with spectrophotometers of different resolution. Journal of Plant Physiology, v.144, p.307-3013, 1994.

WEST, D.W. Stress physiology in trees-salinity. Acta Horticulture, v.175, p.322-329, 1986.

ZANANDREA, L.; NASSI, F.M.; TURCHETTO, A.C.; BRAGA, E.J.B.; PETERS, J.Á.; BACARIN, M.A. Efeito da salinidade sob parâmetros de fluorescência em Phaseolus vulgaris. Revista Brasileira Agrociência, v.12, p.157-161, 2006. 